\title{
Medical devices for restless legs syndrome - clinical utility of the Relaxis pad
}

This article was published in the following Dove Press journal:

Therapeutics and Clinical Risk Management

3 December 2015

Number of times this article has been viewed

\author{
Ulrike H Mitchell \\ Department of Exercise Sciences, \\ Brigham Young University, Provo, \\ UT, USA
}

Correspondence: Ulrike H Mitchell Department of Exercise Sciences, Brigham Young University, SFH \# 268, Provo, UT 84602, USA

Tel + I 80I 4223344

Email rike_mitchell@byu.edu

\begin{abstract}
Restless Legs Syndrome or Willis-Ekbom Disease, a neurosensory disorder, can be treated with pharmaceuticals or conservatively. This review focuses on conservative treatments, more specifically on treatments with medical devices. Two modes of action, enhancement of circulation and counter stimulation, are introduced. Medical devices that use enhancement of circulation as their mechanism of action are whole body vibration, pneumatic compression, and near-infrared light. Medical devices that use counter stimulation include transcutaneous electrical nerve stimulation and the vibration Relaxis pad. The clinical utility of the Relaxis pad and its place in therapy is proposed.
\end{abstract}

Keywords: whole body vibration, pneumatic compression, near-infrared light, conservative treatment, RLS/WED

\section{Introduction to the epidemiology of restless legs syndrome}

Restless legs syndrome (RLS), or now known by its newer name Willis-Ekbom disease (WED) is one of the most prevalent neurological disorders in Europe and North America, affecting approximately $10 \%$ of the population, with women being afflicted almost twice as often as men. ${ }^{1,2}$ Its pathogenesis is uncertain. As there are no biomarkers or definitive measurable clinical findings that can clearly implicate RLS/ WED, its diagnosis is based primarily on subjective complaints. The International Restless Legs Syndrome Study Group 3 developed a five-item "essential diagnostic criteria" questionnaire with which the patient can be diagnosed.

The usual presentation of RLS/WED is characterized by a strong urge to move, accompanied, or caused by uncomfortable or even distressing paresthesia of the legs described as a "creeping, tugging, pulling" feeling. ${ }^{4}$ The symptoms often become worse as the day progresses, leading to sleep disturbances or sleep deprivation, which further result in impairment of alertness and daytime functions. ${ }^{5}$ Approximately $80 \%$ of patients with RLS/WED present with periodic limb movement during sleep, ${ }^{6}$ but the finding is not specific to RLS.

\section{Approaches used to treat symptoms of RLS/WED}

RLS/WED can be classified as "primary" (genetic or idiopathic), or "secondary" (related to other medical or neurological disorders). ${ }^{7}$ The treatment for the latter entails taking care of the underlying conditions, which then, as per definition, should decrease or even abolish RLS/WED symptoms. The treatment for primary RLS/WED consists of pharmacological agents (eg, dopaminergic drugs), ${ }^{7,8}$ conservative options, ${ }^{9}$ or a combination thereof. Conservative or nondrug-related treatment options can be further subdivided into medical devices and no (medical) device. This review will focus on the 


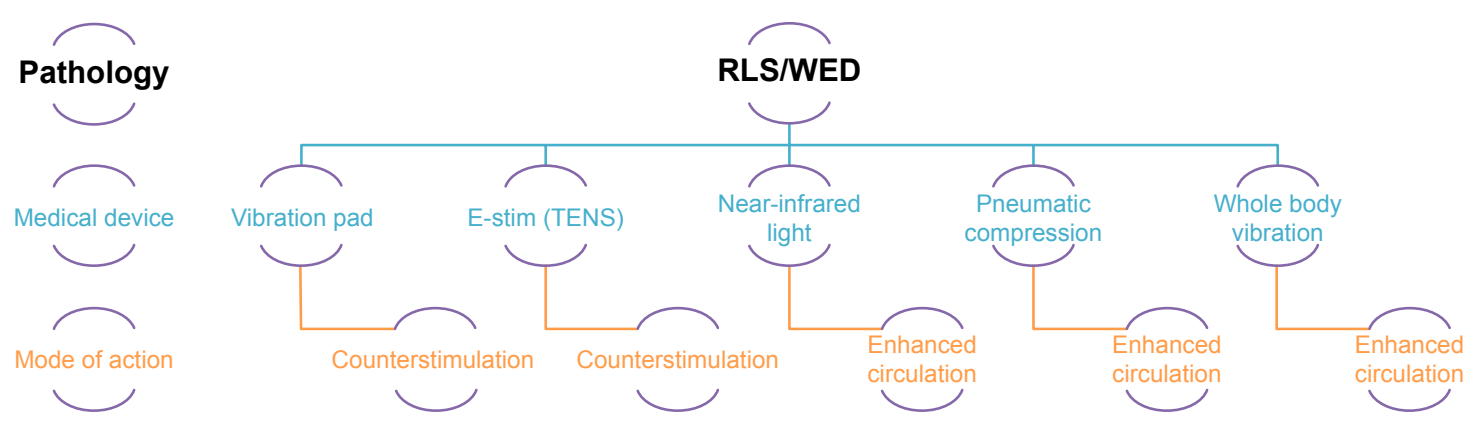

Figure I Review of the current medical devices and their mode of action.

Abbreviations: RLS/WED, restless legs syndrome/Willis-Ekbom disease; TENS, transcutaneous electrical nerve stimulation.

use of medical devices for RLS/WED, their mode of action, safety and tolerability, some patient-focused perspectives, and cost. Figure 1 shows an overview of current medical devices and their mode of action. The efficacy of medical devices in reducing periodic limb movement is not addressed in this paper since there are no published data on this subject. There are also no published papers addressing long-term use of medical devices used for the treatment of RLS/WED.

\section{Review of the current medical devices and their mode of action Mode of action is enhanced circulation}

Some authors believe that the RLS/WED-typical urge to move is the result of a feedback mechanism originating in the muscle or other tissue that signals low oxygenation ${ }^{10-12}$ and that the consequent movement and muscle contractions lead to the desired enhanced oxygen supply. In fact, this "vascular hypothesis" is one of the first modern day (1940s and 1950s) propositions that attempts to explain the etiology of RLS/WED symptoms. ${ }^{13}$

\section{Whole-body vibration}

Currently available, whole-body vibration (WBV) devices deliver vibration through oscillating plates using two different systems: either reciprocating vertical displacements on the left and right side of a fulcrum, or the whole plate oscillating uniformly up and down. ${ }^{14}$ Vibration frequency and vertical displacement vary according to different settings and yield different amounts of acceleration. Investigations using healthy individuals have shown that WBV results in endothelial shear stress ${ }^{15}$ that is sufficient to produce nitric oxide (NO), ${ }^{16}$ a powerful vasodilator. This leads to a decrease in vascular resistance, an increase in skin blood flow, ${ }^{17,18}$ and augmented muscle blood volume. ${ }^{19}$
Safety and tolerability

A great safety concern with WBV is the acceleration transmitted through the axial and appendicular skeleton, and the related potential damage to vision and hearing. ${ }^{20,21}$ A recent study ${ }^{21}$ evaluated platform-to-head acceleration transmissibility and found that greater knee flexion angles (ie, $\leq 40$ degrees) and higher frequencies (ie, $50 \mathrm{~Hz}$ was better than $40 \mathrm{~Hz}$, which was better than 30 and $20 \mathrm{~Hz}$ ) yielded less transmissibility and thus, safer vibration. Knee angles of 0 degrees or when knees were "locked out" were found to be very uncomfortable (and unsafe). Safety and tolerability, as well as positive and adverse effects are specific to frequency, magnitude, acceleration, and duration. ${ }^{22}$

WBV devices are not a mainstay in the treatment of RLS/WED symptoms. No information on patient satisfaction or adherence is available.

\section{Efficacy}

There are no published papers on the efficacy of WBV and RLS/WED symptoms. However, one study ${ }^{23}$ assessed blood flow responses in feet of subjects with RLS/WED before and after a $10 \times 30$ seconds bout of WBV and compared them to controls. The results showed a significant difference in blood flow responses between subjects with RLS/WED and healthy subjects. The authors suggested further research into the use of WBV as a possible treatment option.

\section{Cost}

Cost of WBV devices vary between US \$200 and US \$2,500. They can be found in many fitness centers, offered as part of a workout program.

\section{Pneumatic compression devices}

A pneumatic compression device (PCD) usually consists of inflatable sleeves that are positioned around the foot and 
calf. Intermittently and cyclically, the foot and then the calf sleeve inflate to supply high pressure, which is followed by no pressure. ${ }^{24} \mathrm{~A}$ motorized pump system is necessary to provide the sequential pressure build-up. PCDs are usually used in the prophylaxis of deep vein thrombosis. It is hypothesized that vascular compression stimulates the release of endothelial mediators (ie, NO) ${ }^{25}$ that increase blood flow and thus modulate RLS/WED symptoms. It is also postulated that intermittent compression, which enhances venous and lymphatic drainage, could relieve subclinical ischemia. ${ }^{26}$

\section{Safety and tolerability}

There are no data on the safety and tolerability from patients with RLS/WED. The information presented here is derived from studies that used patients with different pathologies. Some patients have complained of pain in the compression sleeve ${ }^{24}$ and discomfort with inflation of the sleeve. ${ }^{27}$ Other complaints include sweating and itching in the sleeve. ${ }^{27}$ Some patients had a problem adhering to the 1-hour treatment duration. ${ }^{24}$

\section{Efficacy}

Several studies ${ }^{26,28,29}$ found a significant decrease of RLS/ WED symptoms, as well as improvement of quality of life measures and decreased levels of sleepiness and fatigue with the use of PCD. Even a long-term follow-up for some of the patients at 3-6 months after treatment demonstrated that all of them continued to have only mild symptoms. ${ }^{29}$ However, not all studies showed the same positive results. In a letter to the editor, the same primary author ${ }^{30}$ describes a follow-up study using PCD with patients with RLS/WED but did not obtain any different results in the treatment group compared with the control group. One study, using patients with peripheral arterial disease, found that PCD actually decreased oxygenation at the foot and showed a mean reduction in blood flow. ${ }^{24}$

\section{Cost}

PCDs are usually not purchased, but rented.

\section{Near-infrared light}

Near-infrared (NIR) light has a wavelength range from approximately $750-1,000 \mathrm{~nm}$, compared with visible light, which is approximately $380-740 \mathrm{~nm}$. Because of this, it can penetrate the skin deeper than visible light ${ }^{31}$ and can affect blood flow. The proposed circulation-enhancing quality of NIR therapy is based on its ability to generate NO in the endothelium by activating the enzyme Nitric Oxide Synthase 3 (NOS-3). ${ }^{32,33}$ NO then quickly diffuses into the smooth muscle of the endothelium where it activates guanylate cyclase. A cascade of events follow and finally culminate in vasodilation and consequently increased local blood flow. The discomfort that accompanies the RLS/ WED-related urge to move could be caused by the lack of tissue oxygen, which would be offset by an increase in blood flow. The NIR devices usually consist of a base power unit and one to four pads that are applied and attached to the lower leg.

\section{Safety and tolerability}

One study ${ }^{34}$ evaluated tissue heating at different levels: at the skin-diode interface, $0.5,1$, and $1.5 \mathrm{~cm}$ tissue depth. The results showed that the biggest temperature increase occurred on the skin surface (to approximately $40^{\circ} \mathrm{C}$ ), which is considered safe for healthy subjects.

\section{Efficacy}

NIR has been found to be effective in the treatment of RLS/WED. ${ }^{35-38}$ Most studies have used 30-minute treatments, three times a week for 4 weeks. In one study, ${ }^{35}$ the treatment group had a significantly greater improvement in RLS/WED symptoms than the sham treatment group with lasting significant improvements after 4 weeks posttreatment when compared with baseline.

\section{Cost}

NIR devices can be bought from dealers or over the Internet; they range in price between US \$400 and US \$1,200.

\section{Mode of action is counterstimulation}

Some authors believe that the unpleasant sensations associated with RLS/WED are somatic hallucinations ${ }^{39}$ that originate in the brain and are projected into the legs (or the arms). When counterstimulations, such as tactile or vibration stimuli, are sent to the brain, they supersede the afferent input (eg, some RLS/WED symptoms) and modulate those symptoms. This phenomenon is usually explained by the "gate-control theory" proposed by Melzack and Wall in 1965, ${ }^{40}$ which has since been modified slightly: information traveling to the brain in large-diameter nerves (touch, heat, cold) and information traveling to the brain in small-diameter nerves (C-fibers) have to pass the substantia gelatinosa before reaching the transmission cell (T-cell), which then sends the respective information to the brain. The "gate" to the $\mathrm{T}$-cell is usually closed, inhibiting redundant nonpain and constant nociceptive transmission from the periphery to the 
T-cell. However, when C-fibers suddenly send information on painful peripheral stimulation, this opens the gate to the T-cells that then allows the information to be transmitted centrally to the thalamus and cortex where it is interpreted as pain. When, at this point, the large diameter and faster nerves are excited with tactile or vibration stimuli, this new information can override the transmission of pain and thus "close the gate".

\section{E-stim (TENS)}

Transcutaneous electrical nerve stimulation (TENS) is the application of electric current through electrodes placed on the skin, usually for pain control. ${ }^{41}$ The current is produced by a portable battery-operated device that is usually connected to the skin using two or more electrodes. Pulse width, frequency, and intensity can be altered, depending on the desired outcome. Higher frequency $(>50 \mathrm{~Hz})$ stimulation is usually delivered at lower intensities that are sensory only, while lower frequency $(<10 \mathrm{~Hz})$ stimulation is usually used with higher intensity and designed for muscle contraction. Low frequency TENS is also known to cause the release of opioids and as such has longer lasting effects..$^{41,42}$ Prolonged administration of TENS ( $<4$ days) causes opioid tolerance at spinal receptors, meaning that it will be less effective. ${ }^{41}$ It has been suggested to modulate the frequency used between high and low to delay the development of analgesic tolerance. ${ }^{41}$ TENS is usually administered to the site of pain and treatment times vary from 30 minutes to several hours.

\section{Safety and tolerability}

TENS treatments are considered safe and are tolerated well. Some patients might develop a rash at the electrode sites if they are left on too long.

\section{Efficacy}

There is surprisingly little information on the effectiveness of TENS in decreasing symptoms associated with RLS/WED. One case report provides information on a patient with RLS/ WED-like symptoms ${ }^{43}$ who experienced complete pain relief with a combination treatment of TENS and vibration. Adherence to established protocols and compliance with self-administered treatment has been shown to be poor for patients with low back pain. ${ }^{44}$

\section{Cost}

TENS units can be purchased in medical stores or online; their cost is between US $\$ 20$ and $>$ US $\$ 300$.

\section{Vibration (Relaxis) pad}

Relaxis pads consist of a pad, controller, and power supply (standard and battery operated). The pads are supplied in sizes small ( $\left.15^{\prime \prime} \times 17^{\prime \prime}\right)$, medium ( $\left.16^{\prime \prime} \times 17^{\prime \prime}\right)$, or large $\left(17^{\prime \prime} \times 23^{\prime \prime}\right)$ and the vibration source is built into the foam. The controller is used for the adjustment of vibration intensity and time. The built-in default program consists of a 35-minute therapy cycle: during the first 30 minutes, vibration is provided, and in the last 5 minutes, the vibration intensity is slowly reduced until it shuts off on its own. This pad is meant exclusively for the treatment of RLS/WED symptoms and has shown to improve the quality of sleep. ${ }^{39,45}$

\section{Safety and tolerability}

The Relaxis pad is considered safe when used correctly. This device should not be used by patients who have been diagnosed with deep venous thrombosis in either leg during 6 months prior to use because of the known potential to dislodge or break up the clot. ${ }^{45}$ The controller and pad have been shown to warm up. ${ }^{45}$ Approximately $10 \%$ of the patients found the vibration pad irritating. ${ }^{46}$ Seventeen of the 158 patients experienced adverse events, most of them described as temporary worsening of symptoms, which stopped with disuse of the pad. ${ }^{39}$

\section{Efficacy}

Studies ${ }^{39,46}$ have shown that sleep was significantly improved in subjects using the vibration pad compared to those using a sham pad. It was shown ${ }^{46}$ that the pads yield the same sleep improvement over a 4-week use when compared with Food and Drug Administration-approved RLS drugs used over the same amount of time, but without the severe side the drugs can have.

\section{Cost}

This pad can be obtained by prescription only; its cost is between US $\$ 850$ and US $\$ 1,100$, depending on the model and size.

\section{Conclusion and its place in therapy}

Sleep disturbances or sleep deprivation, with resulting impairment of alertness and daytime functions, are major problems associated with RLS/WED. ${ }^{5}$ These vibration pads have been shown to significantly improve sleep, as measured on the Medical Outcomes Study Sleep Scale. ${ }^{47}$ Compared with sham treatment, the vibration pads are not more effective in reducing RLS severity, ${ }^{39}$ as measured by the International Restless Legs Syndrome Study Group rating scale for restless legs syndrome, ${ }^{48}$ but significantly more effective in 
improving sleep quality. ${ }^{39}$ Compared with the other medical devices discussed in this review, the Relaxis pad is the only one meant exclusively for the treatment of RLS/WED.

\section{Disclosure}

Ulrike $\mathrm{H}$ Mitchell has a pending patent for the use of near infrared light as treatment for RLS. The author reports no other conflicts of interest in this work.

\section{References}

1. Benes H. Was gibt es Neues zum Restless-legs-Syndrom? Psychoneuro. 2004;30(8):438-443.

2. Berger K, Luedemann J, Trenkwalder C, John U, Kessler C. Sex and the risk of restless legs syndrome in the general population. Arch Intern Med. 2004;164:196-202.

3. Allen R, Picchietti D, Hening W, Trenkwalder C, Walters A, Montplaisi J. Restless legs syndrome: diagnostic criteria, special considerations, and epidemiology. A report from the restless legs syndrome diagnosis and epidemiology workshop at the National Institutes of Health. Sleep Med. 2003;4:101-119.

4. Ekbom K. Restless legs syndrome. Neurology. 1960;10:868-873.

5. Kushida C, Allen R, Atkinson M. Modeling the causal relationship between symptoms associated with restless legs syndrome and the patient-reported impact of RLS. Sleep Med. 2004;5:485-488.

6. Montplaisir J, Boucher S, Poirier G, Lavigne G, Lapierre O, Lesperance P. Clinical, polysomnographic, and genetic characteristics of restless legs syndrome: a study of 133 patients diagnosed with new standard criteria. Mov Disord. 1997;12(1):61-65.

7. Oertel W, Trenkwalder C, Zucconi M, et al. State of the art in restless legs syndrome therapy: practice recommendations for treating restless legs syndrome. Mov Disord. 2007;22:S466-S475.

8. Thorpy M. New paradigms in the treatment of restless legs syndrome. Neurology. 2005;64(Suppl 3):S28-S33.

9. Mitchell UH. Nondrug-related aspect of treating Ekbom disease, formerly known as restless legs syndrome. Neuropsychiatr Dis Treat. 2011;7: 251-257.

10. Larsson BW, Kadi F, Ulfberg J, Aulin KP. Skeletal muscle morphology in patients with restless legs syndrome. Eur Neurol. 2007;58(3): 133-137.

11. Wahlin-Larsson B, Ulfberg J, Aulin KP, Kadi F. The expression of vascular endothelial growth factor in skeletal muscle of patients with sleep disorders. Muscle Nerve. 2009;40(4):556-561.

12. Salminen AV, Rimpila V, Polo O. Peripheral hypoxia in restless legs syndrome (Willis-Ekbom disease). Neurology. 2014;82(21): 1856-1861.

13. Coccagna G, Vetrugno R, Lombardi C, Provini F. Restless legs syndrome: an historical note. Sleep Med. 2004;5:279-283.

14. Cardinale M, Wakeling J. Whole body vibration exercise: are vibrations good for you? Br J Sports Med. 2005;39(9):585-589; discussion 589

15. Mester J, Kleinoder H, Yue Z. Vibration training: benefits and risks. J Biomech. 2006;39(6):1056-1065.

16. Sackner MA, Gummels E, Adams JA. Nitric oxide is released into circulation with whole-body, periodic acceleration. Chest. 2005;127(1): 30-39.

17. Lohman E, Petrofsky J, Maloney-Hinds C, Betts-Schwab H, Thorpe D. The effect of whole body vibration on lower extremity skin blood flow in normal subjects. Med Sci Monit. 2007;13(2): CR71-CR76.

18. Games KE, Sefton JM, Wilson AE. Whole-body vibration and blood flow and muscle oxygenation: a meta-analysis. $J$ Athl Train. 2015;50(5): 542-549.

19. Kerschan-Schindl K, Grampp S, Henk C, et al. Whole-body vibration exercise leads to alterations in muscle blood volume. Clin Physiol. 2001; 21(3):377-382.
20. Muir J, Kiel DP, Rubin CT. Safety and severity of accelerations delivered from whole body vibration exercise devices to standing adults. J Sci Med Sport. 2013;16(6):526-531.

21. Caryn RC, Hazell TJ, Dickey JP. Transmission of acceleration from a synchronous vibration exercise platform to the head. Int J Sports Med. 2014;35(4):330-338.

22. Hadi SC, Delparte JJ, Hitzig SL, Craven BC. Subjective experiences of men with and without spinal cord injury: tolerability of the juvent and WAVE whole body vibration plates. PM R. 2012;4(12):954-962.

23. Mitchell U, Johnson P. Vibration and skin blood flow changes in subjects with restless legs syndrome. J Parkinsonism Restless Legs Syndrome. 2014;4:9-16.

24. Manfredini F, Malagoni AM, Felisatti M, et al. Acute oxygenation changes on ischemic foot of a novel intermittent pneumatic compression device and of an existing sequential device in severe peripheral arterial disease. BMC Cardiovasc Disord. 2014;14:40.

25. Sun D, Huang A, Recchia F, et al. Nitric oxide-mediated arteriolar dilation after endothelial deformation. Am J Physiol Heart Circ Physiol. 2001; 280:H714-H721.

26. Lettieri C, Eliasson A. Pneumatic compression devices are an effective therapy for restless legs syndrome: a prospective, randomized, doubleblinded, sham-controlled trial. Chest. 2009;135:74-80.

27. Moore K, Nichols-Willey J, Orlosky-Novack J. Enhancing patient outcomes with sequential compression device therapy. Am Nurse Today. 2013;8(8). Available from: http://www.americannursetoday. com/enhancing-patient-outcomes-with-sequential-compression-devicetherapy/. Accessed August 25, 2015.

28. Eliasson A, Lettieri C. Sequential compression devices for treatment of restless legs syndrome. Medicine. 2007;86(6):317-323.

29. Rajaram S, Shanahan J, Ash C, Walters A, Weisfogel G. Enhanced external counter pulsation (EECP) as a novel treatment for restless legs syndrome (RLS): a preliminary test of the vascular neurologic hypothesis for RLS. Sleep Med. 2005;6:101-106.

30. Rajaram S, Rudzinskiy P, Walters A. Enhanced external counter pusation (EECP) for restless legs syndrome (RLS): preliminary results in a parallel double-blind study. Sleep Med. 2006;7:390-391.

31. Stolik S, Delgado J, Perez A, Anasagasti L. Measurement of the penetration depths of red and near infrared light in human "ex vivo" tissues. J Photochem Photobiol B. 2000;57:90-93.

32. Matsunga $\mathrm{K}$, Furchgott $\mathrm{R}$. Interaction of light and sodium nitrite in producing relaxation of rabbit aorta. J Pharmacol Exp Ther. 1989;248(2): 687-695.

33. Buga G, Gold M, Fukuto J, Ignarro L. Shear stress induced release of nitric oxide from endothelial cells grown on beads. Hypertension. 1991;17: 187-193.

34. Mitchell UH, Johnson AW, Myrer JW, Hager RL, Eggett DL. A randomized single-blind controlled trial comparing two monochromatic near-infrared light devices: implications for tissue heating and safety. Am J Phys Med Rehabil. 2012;91(9):789-796.

35. Mitchell U. Use of near-infrared light to reduce symptoms associated with restless legs syndrome: a case report. $J$ Med Case Reports. 2010;4:286

36. Mitchell U, Johnson A, Myrer J. Comparison of two infrared devices in their effectiveness in reducing symptoms associated with RLS. Physiother Theory Pract. 2010;27(5):352-359.

37. Mitchell UH, Myrer JW, Johnson AW, Hilton SC. Restless legs syndrome and near-infrared light: an alternative treatment option. Physiother Theory Pract. 2011;27(5):345-351.

38. Guffey JS, Motts S, Barymon D, et al. Using near infrared light to manage symptoms associated with restless leg syndrome. Physiother Theory Pract. 2015 in press.

39. Burbank F, Buchfuhrer M, Kopjar B. Sleep improvement for restless legs syndrome patients. Part I: pooled analysis of two prospective, double-blind, sham-controlled, multi-center randomized clinical studies of the effects of vibrating pads on RLS symptoms. $J$ Parkinsonism Restless Legs Syndrome. 2013;2013(3):1-10.

40. Melzack R, Wall PD. Pain mechanisms: a new theory. Science. 1965; 150:971-979. 
41. DeSantana JM, Walsh DM, Vance C, Rakel BA, Sluka KA. Effectiveness of transcutaneous electrical nerve stimulation for treatment of hyperalgesia and pain. Curr Rheumatol Rep. 2008;10(6):492-499.

42. Basbaum AI, Fields HL. Endogenous pain control mechanisms: review and hypothesis. Ann Neurol. 1978;4(5):451-462.

43. Guieu R, Tardy-Gervet MF, Blin O, Pouget J. Pain relief achieved by transcutaneous electrical nerve stimulation and/or vibratory stimulation in a case of painful legs and moving toes. Pain. 1990; 42(1):43-48.

44. Pallett EJ, Rentowl P, Johnson MI, Watson PJ. Implementation fidelity of self-administered transcutaneous electrical nerve stimulation (TENS) in patients with chronic back pain: an observational study. Clin J Pain. 2014;30(3):224-231.
45. Stop your restless legs symptoms; 2015. Available from: http:// myrelaxis.com/us/. Accessed August 27, 2015.

46. Burbank F, Buchfuhrer M, Kopjar B. Improving sleep for patients with restless legs syndrome. Part II: meta-analysis of vibration therapy and drugs approved by the FDA for treatment of restless legs syndrome. J Parkinsonism Restless Legs Syndrome. 2013;3:11-22.

47. Allen RP, Kosinski M, Hill-Zabala CE, Calloway MO. Psychometric evaluation and tests of validity of the Medical Outcomes Study 12-item Sleep Scale (MOS sleep). Sleep Med. 2009;10(5):531-539.

48. Walters AS1, LeBrocq C, Dhar A, et al; The International Restless Legs Syndrome Study Group. Validation of the International Restless Legs Syndrome Study Group rating scale for restless legs syndrome. Sleep Med. 2003;4:121-132.

\section{Publish your work in this journal}

Therapeutics and Clinical Risk Management is an international, peerreviewed journal of clinical therapeutics and risk management, focusing on concise rapid reporting of clinical studies in all therapeutic areas, outcomes, safety, and programs for the effective, safe, and sustained use of medicines. This journal is indexed on PubMed Central, CAS,
EMBase, Scopus and the Elsevier Bibliographic databases. The manuscript management system is completely online and includes a very quick and fair peer-review system, which is all easy to use. Visit http://www.dovepress.com/testimonials.php to read real quotes from published authors. 